\title{
Study on Airborne Radionuclide Dispersion in Floating Nuclear Power Plant under the Loss-of-Coolant Accident
}

\author{
Shuliang Zou $\mathbb{D},^{1,2}$ Na Liu $\mathbb{D}^{1,2}$ and Binhai Huang $\mathbb{D}^{1,2}$ \\ ${ }^{1}$ School of Environmental and Safety Engineering, University of South China, Hengyang, Hunan 421001, China \\ ${ }^{2}$ Key Laboratory of Hunan Province of Nuclear Emergency of Safety Technology \& Equipment, University of South China, \\ Hengyang, Hunan 421001, China \\ Correspondence should be addressed to Shuliang Zou; zousl2013@126.com
}

Received 30 May 2021; Revised 31 July 2021; Accepted 24 August 2021; Published 2 September 2021

Academic Editor: Massimo Zucchetti

Copyright ( $) 2021$ Shuliang Zou et al. This is an open access article distributed under the Creative Commons Attribution License, which permits unrestricted use, distribution, and reproduction in any medium, provided the original work is properly cited.

\begin{abstract}
Floating nuclear power plant is a kind of nuclear power plant on a barge moored specifically in an area of the sea. In order to study the factors influencing airborne radionuclide dispersion induced by the loss-of-coolant accident in floating nuclear power plant, the floating nuclear power plant platform was taken as the research object, and the dispersion of airborne radionuclide under combined conditions of platform positions, wind directions, and break directions (north, south, west, and east) was simulated by the CFD (computational fluid dynamics) method. The results show that northern and southern breaks have less dangerous island area than western and eastern ones but have more platform dangerous area than the western and eastern ones. The risk of the southern break is the greatest, and that of the western break is the least. Rotating the floating nuclear power plant platform in a certain angle can reduce the damage of loss-of-coolant accident. The effects of the dose received by the personnel under the condition of the severe accident were evaluated based on previous research, showing that the inhalation effective dose and the effective dose of plume immersion exposure were less than the radiation dose limit of $0.25 \mathrm{~Sv}$ within two hours in the accident. The results of the study can provide reference for the design of floating nuclear power plant platform and the formulation of emergency plan.
\end{abstract}

\section{Introduction}

Floating nuclear power plant, the organic combination of ship engineering and nuclear engineering, is a new trend in international nuclear energy applications because it can provide effective and reliable power for offshore oil exploitation, remote islands, and seawater desalination [1].

For floating nuclear power plants, the current research focuses on the construction and design of floating nuclear power plant platforms. Rafiul Abdussami et al. introduced the design, development status, and development plan of floating nuclear power plants in Bangladesh and considered the impact of special events of earthquake and tsunami on floating nuclear power plants in Bangladesh [2]. Paik and Park employed the LS-DYNA nonlinear finite-element method for the structural crashworthiness analysis of offshore floating nuclear power plant [3]. Geon-Woo et al. performed a scaling analysis for single-phase natural circulation and derived similarity criteria for inclination, frame acceleration, and rotational motion conditions in floating nuclear reactors [4]. In China, scientists are focusing on designing ACPR50S and ACP100S to exploit offshore oil and gas, develop island, and desalinate seawater.

Floating nuclear power plants use small modular reactor technology. Although the frequency of severe accidents in SMRs (small modular reactors) is expected to be lower than that of traditional nuclear power plants due to their outstanding safety features, severe accidents of SMRs cannot be totally avoided. Specifically, floating nuclear power plants lack adequate prevention and mitigation measures due to the limitation of space and load capability. Furthermore, floating nuclear power plants suffer much more complicated environment uncertainty since they operate under ocean condition. Thus, the probability of severe accidents of floating 
nuclear power plant SMRs might be relatively higher than the onshore SMRs [5]. Therefore, a severe nuclear accident involving radionuclide leakage in atmosphere would pose a serious threat to personnel on the platform, the environment, and civilians in the vicinity of the floating nuclear power plant.

However, research focusing on emergency rescue after accidents, specifically for the radionuclide dispersion in the atmosphere after a serious accident, is still limited.

Computational fluid dynamics (CFD) has been able to simulate the complex fluid flows with a quantitative and qualitative description of the temporal and spatial change of the flow field [6] and is widely used in the migration and dispersion of pollutants [7-9]. In the nuclear field, CFD is mainly used in structural design such as observing the channel airflow patterns and heat dissipation characteristics of dry storage casks for spent nuclear fuel [10], evaluating the hydrodynamic FCs of a combined emergency stop and control valve to be employed in an ultra-supercritical (USC) turbine system for power plant [11], and simulating the cavitation flow of a nuclear venturi tube [12]. There is relatively little research on radionuclide dispersion, and research has been aiming at radionuclide dispersion on onshore nuclear power plants $[13,14]$. Wang et al. adopted computational fluid dynamics (CFD) method to simulate the impact of large cooling tower on the diffusion of gaseous effluent from coastal nuclear power plant [15]. CFD simulations were used to observe the channel airflow patterns and heat dissipation characteristics of dry storage casks for spent nuclear fuel [10]. CFD simulations of dispersion of particles representative of inactive fuel debris simulants were performed by Thomas et al., and results showed a quite good agreement, but some improvements were needed to take into account [16]. The structure and core power of floating nuclear power plants are very different from onshore nuclear power plants, so the source term release characteristics are also different. Therefore, it is necessary to study the law of radionuclide dispersion of floating nuclear power plants.

In view of this, the CFD method was adopted to study the airborne radionuclide dispersion in floating nuclear power plants under the combined conditions of break directions, platform locations, and wind directions in the loss-ofcoolant accident and evaluate the radiation dose under severe accident conditions in this study, which is meaningful for emergency response of floating nuclear power plants.

\section{CFD Control Equation on Gas Dispersion}

2.1. Mass Conservation Equation. The mass conservation equation is called the continuity equation in computational fluid dynamics. It is derived from the basic idea that the net mass value is zero, and its expression is shown in the following equation:

$$
\frac{\partial \rho}{\partial t}+\frac{\partial(\rho u)}{\partial x}+\frac{\partial(\rho v)}{\partial y}+\frac{\partial(\rho w)}{\partial z}=0
$$

where $\rho$ is the density, $t$ is the time, and $u, v$, and $w$ are the velocity vectors in the $x, y$, and $z$ directions, respectively.
2.2. Momentum Conservation Equation. The meaning of the momentum conservation equation is that the object is not subject to external force or the sum of external forces is zero. It is also called the Navier-Stokes equation in fluid mechanics, and its expression is as follows:

$$
\frac{\partial\left(\rho \mu_{i}\right)}{\partial t}+\frac{\partial\left(\rho \mu_{j} \mu_{i}\right)}{\partial x_{j}}=\frac{\partial \tau_{i j}}{\partial x_{j}}-\frac{\partial \rho}{\partial x_{i}}+\rho g_{i}
$$

2.3. Energy Conservation Equation. The law of conservation of energy means that the sum of the generation and disappearance of energy in any closed system does not change, that is, the total energy does not change. The expression of the law of conservation of energy is shown in the following equation:

$$
\frac{\partial(\rho T)}{\partial t}+\frac{\partial\left(\rho \mu_{i} T\right)}{\partial x_{i}}=\frac{\partial}{\partial x_{i}}\left(\frac{\lambda}{C p} \cdot \frac{\partial T}{\partial x_{i}}\right)+S_{r}
$$

where $C p$ is the thermal conductivity of the gas, $T$ is the thermodynamic temperature, and $S_{r}$ represents other viscous dissipation terms.

2.4. Component Conservation Equation. When the gas is diffused, the total amount of the released gas remains constant during the exchange of substances. The equation can be expressed as

$$
\frac{\partial(\rho C)}{\partial t}+\frac{\partial\left(\rho \mu_{i} C\right)}{\partial x_{i}}=\frac{\partial}{\partial x_{i}}\left(T_{C} \frac{\partial_{C}}{\partial x_{i}}\right)+S_{C},
$$

where $C$ is the volume concentration of a certain gas, $T_{C}$ is the dispersion coefficient of the gas, and $S_{C}$ is the production rate of per unit volume of component $C$.

2.5. $k-\varepsilon$ Equation. Time-averaged mass conservation equation is as follows:

$$
\frac{\partial\left(\rho \bar{\mu}_{i}\right)}{\partial t}=0
$$

Time-averaged momentum conservation equation is as follows:

$$
\frac{\partial\left(\rho \bar{\mu}_{i}\right)}{\partial t}+\frac{\partial\left(\rho \bar{\mu}_{i}, \bar{\mu}_{j}\right)}{\partial x_{j}}=-\frac{\partial \bar{\rho}}{\partial x_{i}}+\frac{\partial}{\partial x_{j}}\left(\mu \frac{\partial \bar{\mu}_{i}}{\partial x_{i}}-\rho \bar{\mu}_{i}^{\prime} \bar{\mu}_{j}^{\prime}\right)
$$

\section{CFD Model for the Floating Nuclear Power Plant}

3.1. Scenario Simulation. In order to alleviate the damage caused by severe accidents of floating nuclear power plan, the island power supply scenario of floating nuclear power plant is selected as shown in Figure 1. Taking the loss of water accident as an example, the law of radionuclide dispersion of floating nuclear power plants is studied.

Loss-of-coolant accident (LOCA) refers to the break that causes the reduction or loss of the coolant in the primary 


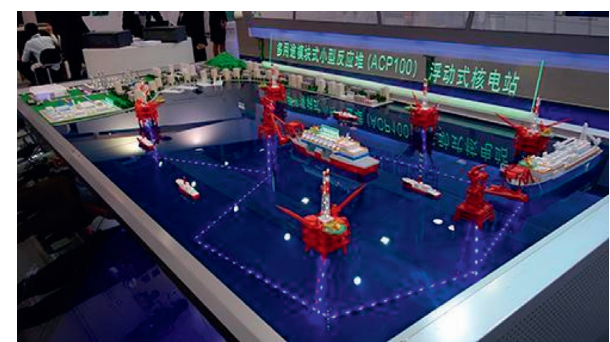

Figure 1: Working scenario of a floating nuclear power plant.

circuit and the failure to take away the reaction heat in time to cause core meltdown [10]. Because the primary loop system of the PWR is in a high-temperature and highpressure operating environment, coupled with radiation damage to the primary circuit equipment, the pipeline breaks or the valve control system fails. In this study, the description of the small break accident sequence of the Korean integrated modular advanced reactor was used as the basis for the compilation of the input card for the MELCOR code.

Then, the scenario diagram is simplified and extracted, and the geometric model diagram is drawn through ICEM as shown in Figure 2. The overall size is $1500 \mathrm{~m} * 900 \mathrm{~m}$ (length $*$ width), and the size of the offshore floating nuclear power plant platform is $140 \mathrm{~m} * 50 \mathrm{~m}$. The layout of the cabins of the floating nuclear power plant is shown in Figure 3. From left to right, they are secondary circuit cabin $(55 \mathrm{~m} * 40 \mathrm{~m})$, the reactor cabin $(35 \mathrm{~m} * 40 \mathrm{~m})$, and the living cabin $(30 \mathrm{~m} * 40 \mathrm{~m})$. The platform structure has a certain effect on the radionuclide dispersion. Therefore, different directions of the break have different impacts on the dispersion. In order to study the related laws, set the north side (A), south side (B), west side (C), and east side (D) as the four breaks.

3.2. Boundary Parameter Setting. In this study, seven boundary conditions: wall1, wall2, xl, up, down, left, and right, are set, and the boundary type is set according to the actual situation. Up, left, and right are open sea areas, corresponding to the upper boundary and two sides of the calculation domain in accordance with the free and fully developed flow conditions, and it is processed as the free outflow boundary during the simulation process. The boundary conditions are set to outflow type. The lower boundary down is the wind speed inlet boundary, set to velocity inlet. The island building wall 1 and the floating nuclear power plant platform wall2 are set to wall, and the radionuclide leakage port $\mathrm{xl}$ is set to velocity inlet.

The $k-\varepsilon$ turbulence model and the component transport model are used in the calculation model, and radionuclide leakage takes the form of mass flow and adopts an incompressible ideal gas model.

3.3. Source Term Data Input. Different from land reactors, floating nuclear power plant reactor is an integrated modular design, whose core power is smaller (about $300 \mathrm{MWe}$ ).

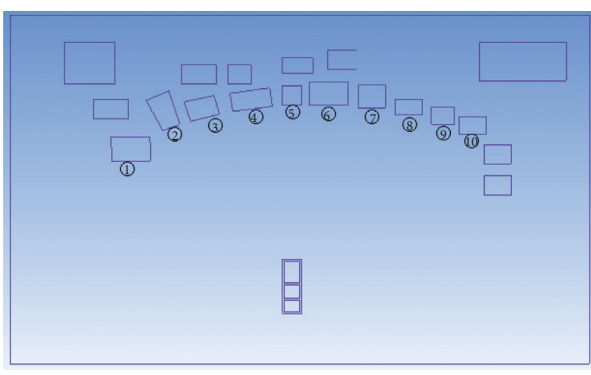

Figure 2: The geometric model.

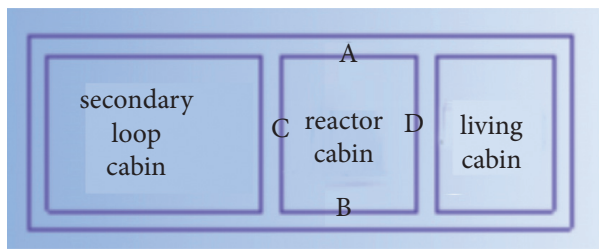

Figure 3: Floating nuclear power plant platform layout.

The steam generator is built in the pressure vessel, and the main coolant circulation pump is directly connected to the pressure vessel [16]. The main coolant pipeline of the primary loop system is omitted, the structure is more compact, and the migration path as well as the speed of source term have changed compared with the traditional reactor.

Based on the above differences, the reactor data in this paper refer to system-integrated modular advanced reactor (SMART) of South Korea, and the simulation accident selects loss-of-coolant accident, which is most likely to occur in marine reactors. MELCOR code is adopted as source term calculation program. The result is shown in Table 1. The radionuclides released into the environment are mainly $\mathrm{Xe}$, $\mathrm{Cs}, \mathrm{I}$, and Te, and the percentage of Xe is the largest, accounting for $95 \%$. The release rates of the main radionuclides are calculated separately, and the release rates of $\mathrm{Xe}, \mathrm{I}$, and Cs are $6.0 \times 10^{3} \mathrm{~Bq} / \mathrm{s}, 4.29 \times 10^{8} \mathrm{~Bq} / \mathrm{s}$, and $1.3 \times 10^{5} \mathrm{~Bq} / \mathrm{s}$, respectively, which are used as the boundary conditions of CFD simulation calculation.

\section{Results and Discussion}

When the sea wind blows to the north, radionuclides are most likely to spread to the island, and the people on the island are in the most dangerous situation. Therefore, in order to ensure the safety of people on the islands, this study focuses on analyzing the influence of this wind direction on radionuclides.

4.1. Results for the Break Location. In order to study the influence of break location, when the wind speed is $4 \mathrm{~m} / \mathrm{s}$ and the radionuclide jet velocity is $10 \mathrm{~m} / \mathrm{s}$, we simulate radionuclide dispersion of the 4 breaks in north side (A), south side (B), west side (C), and east side (D) of the floating nuclear power plant platform, respectively, and the results are shown in Figures 4-7. 
TABLE 1: Environmental release share of various radionuclides.

\begin{tabular}{lccccccc}
\hline Radionuclide & $\mathrm{Xe}$ & $\mathrm{Cs}$ & $\mathrm{I}$ & $\mathrm{Te}$ & Mo & Particle & Others \\
\hline Percentage & $94 \%$ & $2.91 \%$ & $0.1 \%$ & $0.5 \%$ & $0.95 \%$ & $1.5 \%$ & $0.04 \%$ \\
\hline
\end{tabular}

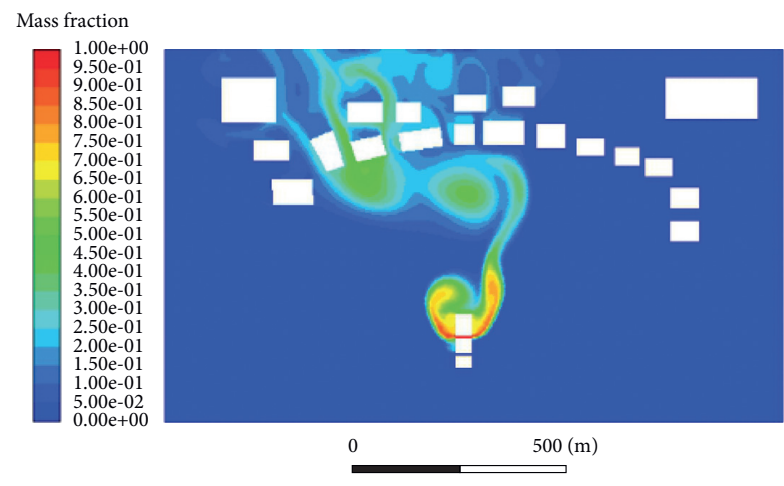

FIGURE 4: Radionuclide dispersion at the northern break.

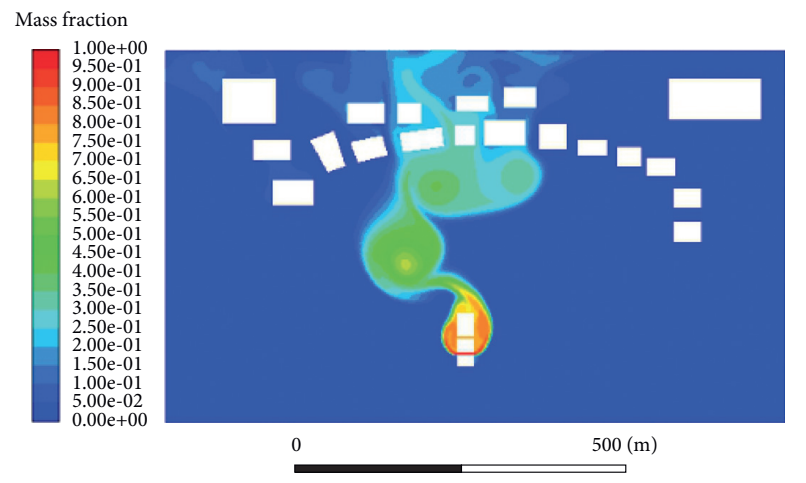

FIgURE 5: Radionuclide dispersion at the southern break.

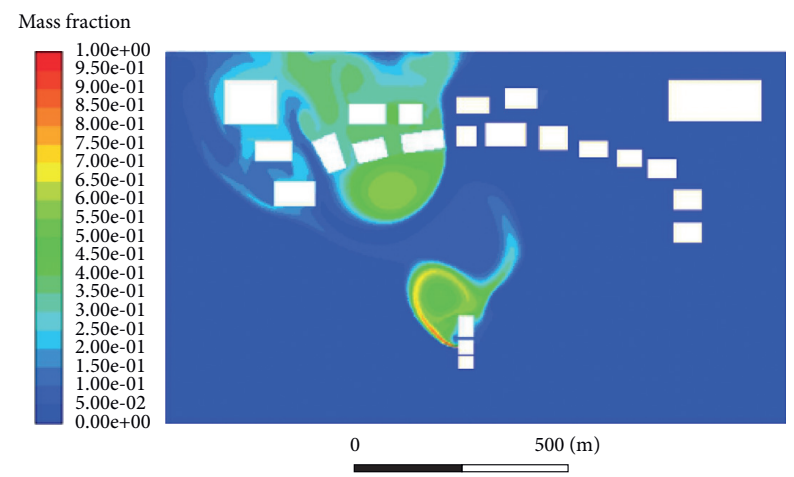

FIGURE 6: Radionuclide dispersion at the western break.

The distribution of radionuclide at four locations is shown in Figures 4-7. In order to further quantify the distribution of radionuclide, the area where the radionuclides reach is set as a dangerous area. The results are shown in the following table.

As shown in Table 2, when a break occurs at the north side (A), the island's dangerous area and dangerous area of floating nuclear power plant platform are $142,325 \mathrm{~m}^{2}$, accounting for $87.6 \%$ of the total; when a break occurs at south

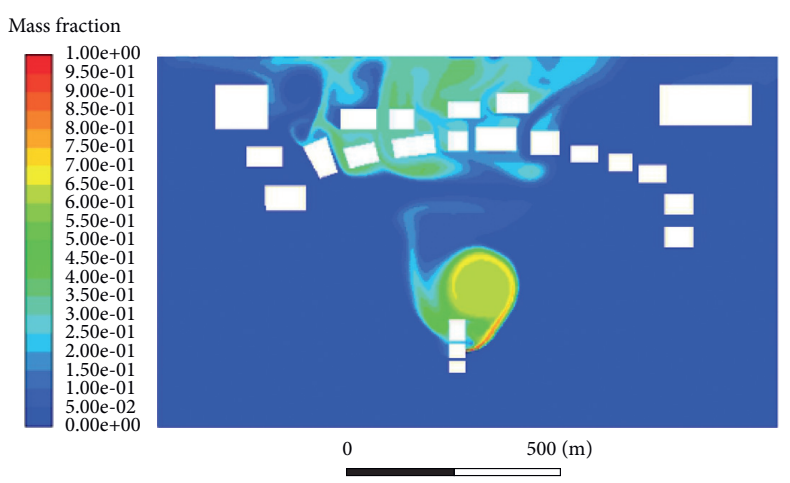

FIGURE 7: Radionuclide dispersion at the eastern break.

side (B), the island's dangerous area and the dangerous area of the platform are $110790 \mathrm{~m}^{2}$, accounting for $99.7 \%$ of the total; when a break occurs at west side (C), the island's dangerous area and the dangerous area of the platform are $192485 \mathrm{~m}^{2}$, accounting for $75.2 \%$ of the total; and when a break occurs at east side (D), the dangerous area of the island and the dangerous area of the platform are $224475 \mathrm{~m}^{2}$, accounting for $99.3 \%$ of the total. From that we get the following:

(1) The total dangerous area of the western (C) break is the smallest, and the total dangerous area of southern break is the largest.

(2) The area and proportion of the dangerous area of the floating nuclear power plant platform at the northern break (A) and southern break (B) are larger than those at the west side (C) and the east side (D), while the area of the island's dangerous area is smaller than that of the western (C) break and eastern (D) break. The main reason is that the two breaks on the north and south sides are located between the secondary loop compartment and the reactor compartment, forming a groove. The leaked radionuclides tend to accumulate in the groove and spread to the platform.

4.2. Results for Hull Placement. In the event of a severe accident, the personnel waiting to be evacuated on the floating nuclear power plant platform cannot move in a wide range, but the movable nature of the floating nuclear power plant can be used to change the direction of the platform hull to change the migration path of radionuclides in order to reduce the risk. Therefore, we study the distribution of radionuclides at the north side (A), south side (B), west side (C), and east side (D) clockwise by $90^{\circ}, 180^{\circ}$, and $270^{\circ}$, respectively, and the distribution of radionuclides at the northern break is shown in Figures 8-10.

As shown in Table 3, when a break occurs at the north side (A), the island's dangerous area and dangerous area of floating nuclear power plant platform are $142,325 \mathrm{~m}^{2}$, accounting for $87.6 \%$ of the total. When the floating nuclear power plant platform rotates $90^{\circ}$ clockwise, the total proportion of island's dangerous area and platform dangerous area is $91 \%$, but its dangerous area is $92,310 \mathrm{~m}^{2}$, which is much smaller than the dangerous area at $0^{\circ}$. Therefore, when 
TABLE 2: The area and proportion of the danger area of the four breaks.

\begin{tabular}{lcccc}
\hline Break location & \multicolumn{2}{c}{$\begin{array}{c}\text { Dangerous area of } \\
\text { Island's dangerous area }\end{array}$} & $\begin{array}{c}\text { cating nuclear power } \\
\text { plant platform }\end{array}$ \\
& Area $\left(\mathrm{m}^{2}\right)$ & Percentage & Area $\left(\mathrm{m}^{2}\right)$ & Percentage \\
\hline North (A) & 141100 & 31.9 & 1225 & 55.7 \\
South (B) & 109140 & 24.7 & 1650 & 75.0 \\
West (C) & 191760 & 43.4 & 725 & 31.8 \\
East (D) & 223400 & 50.5 & 1075 & 48.8 \\
\hline
\end{tabular}

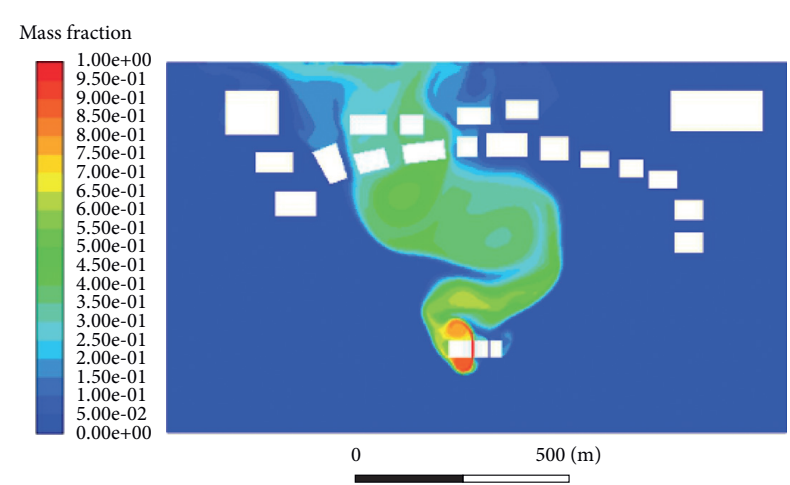

Figure 8: Radionuclide distribution rotating $90^{\circ}$ clockwise at the northern break.

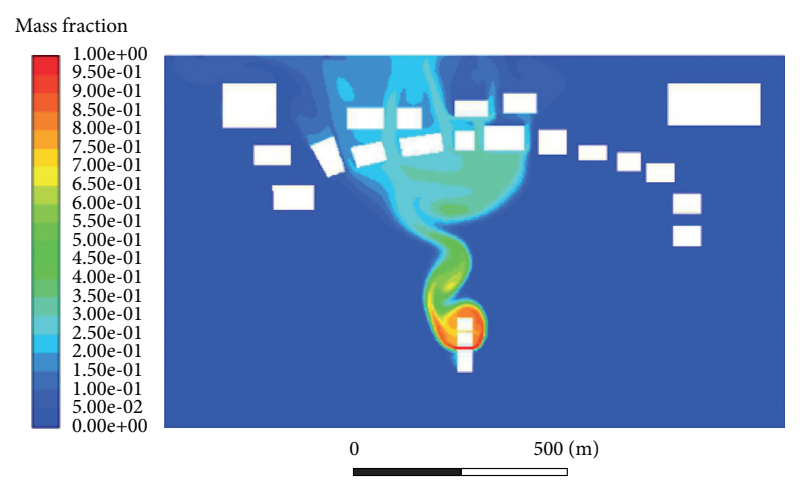

FIGURE 9: Radionuclide distribution rotating $180^{\circ}$ clockwise at the northern break.

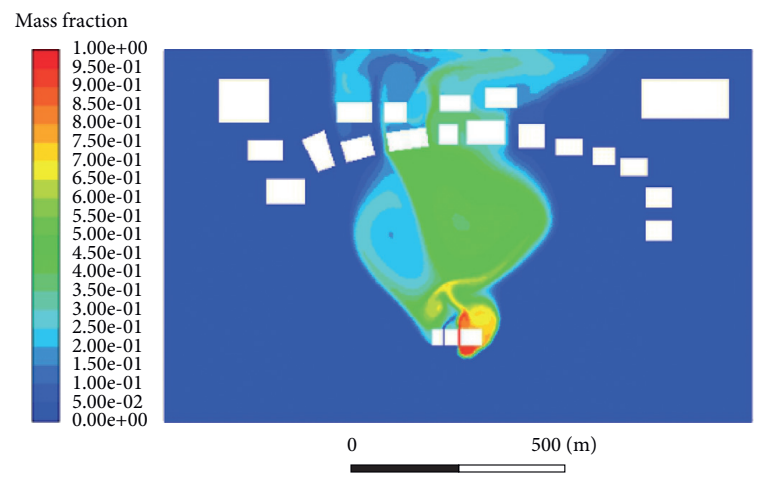

FIGURE 10: Radionuclide distribution rotating $270^{\circ}$ clockwise at the northern break.
TABLE 3: The dangerous area and proportion after rotating at the northern break.

\begin{tabular}{|c|c|c|c|c|}
\hline \multirow[t]{2}{*}{ Rotation angle } & \multicolumn{2}{|c|}{ Island's dangerous area } & \multicolumn{2}{|c|}{$\begin{array}{l}\text { Dangerous area of } \\
\text { floating nuclear power } \\
\text { plant platform }\end{array}$} \\
\hline & Area $\left(\mathrm{m}^{2}\right)$ & Percentage & Area $\left(\mathrm{m}^{2}\right)$ & Percentage \\
\hline $0^{\circ}$ & 141100 & 31.9 & 1125 & 55.7 \\
\hline $90^{\circ}$ & 90780 & 20.5 & 1530 & 69.5 \\
\hline $180^{\circ}$ & 153340 & 41.3 & 1675 & 76.1 \\
\hline $270^{\circ}$ & 204000 & 46.2 & 1875 & 85.2 \\
\hline
\end{tabular}

rotating $90^{\circ}$ clockwise, the risk can be reduced. The proportion of the dangerous area of other rotation angles is greater than that of the non-rotating situation.

The distribution of radionuclide in different angles at southern break is shown in Figures 11-13.

As shown in Table 4, when a break occurs at south side (B), the island's dangerous area and the dangerous area of the platform are $1,107,900 \mathrm{~m}^{2}$, accounting for $99.7 \%$ of the total. When the platform rotates $90^{\circ}$ clockwise, the island's dangerous area and the dangerous area of the platform are $104860 \mathrm{~m}^{2}$, accounting for $91.6 \%$ of the total. When the platform rotates $180^{\circ}$ clockwise, the island's dangerous area and the dangerous area of the platform are $173018 \mathrm{~m}^{2}$, accounting for $83.4 \%$ of the total. When the platform rotates $270^{\circ}$ clockwise, the dangerous area of the island and the dangerous area of the platform are $130,700 \mathrm{~m}^{2}$, accounting for $97.4 \%$ of the total. Therefore, when rotating $90^{\circ}$ clockwise, the total dangerous area and the proportion of the dangerous area are reduced, which can reduce the risk.

The distribution of radionuclide at western break is shown in Figures 14-16.

As shown in Table 5, when a break occurs at west side (C), the dangerous area of the island and the dangerous area of the platform are $192,485 \mathrm{~m}^{2}$, accounting for $75.2 \%$ of the total. When the platform rotates $90^{\circ}$ clockwise, the island's dangerous areas and the dangerous area of the platform are $193,515 \mathrm{~m}^{2}$, accounting for $92.4 \%$ of the total. When the platform rotates $180^{\circ}$ clockwise, the island's dangerous area and the dangerous area of the platform are $240,510 \mathrm{~m}^{2}$, accounting for $106.5 \%$ of the total. When the platform rotates $270^{\circ}$ clockwise, the dangerous area of the island and the dangerous area of the platform are $221700 \mathrm{~m}^{2}$, accounting for $81.8 \%$ of the total. From previous analysis, the western break has the lowest risk. After the platform is rotated, the total dangerous area and total proportion of the dangerous area are larger than those when it is not rotated, so rotating cannot reduce the risk.

The distribution of radionuclide at the eastern break is shown in Figures 17-19.

As shown in Table 6, when a break occurs at east side (D), the dangerous area of the island and the dangerous area of the platform are $224475 \mathrm{~m}^{2}$, accounting for $99.3 \%$ of the total. When the platform rotates $90^{\circ}$ clockwise, the island's dangerous area and the dangerous area of the platform are $242,250 \mathrm{~m}^{2}$, accounting for $93.2 \%$ of the total. When the platform rotates $180^{\circ}$ clockwise, the island's dangerous area and the dangerous area of the platform are $145,100 \mathrm{~m}^{2}$, 


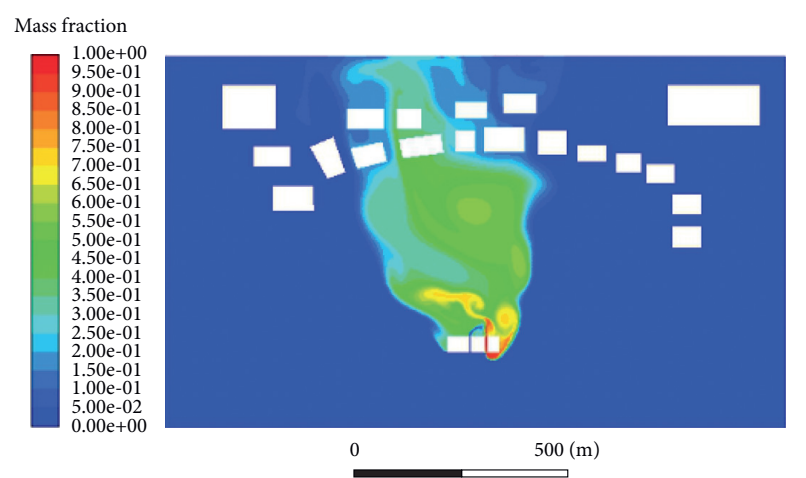

FIGURE 11: Radionuclide distribution rotating $90^{\circ}$ clockwise at the southern break.

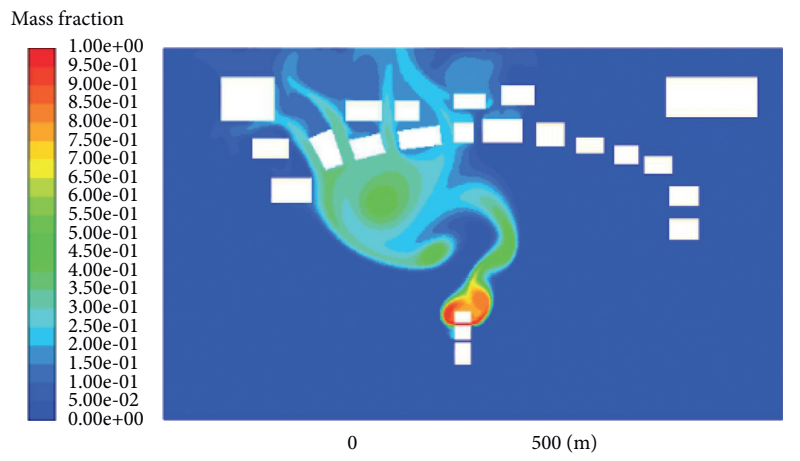

FIGURE 12: Radionuclide distribution rotating $180^{\circ}$ clockwise at the southern break.

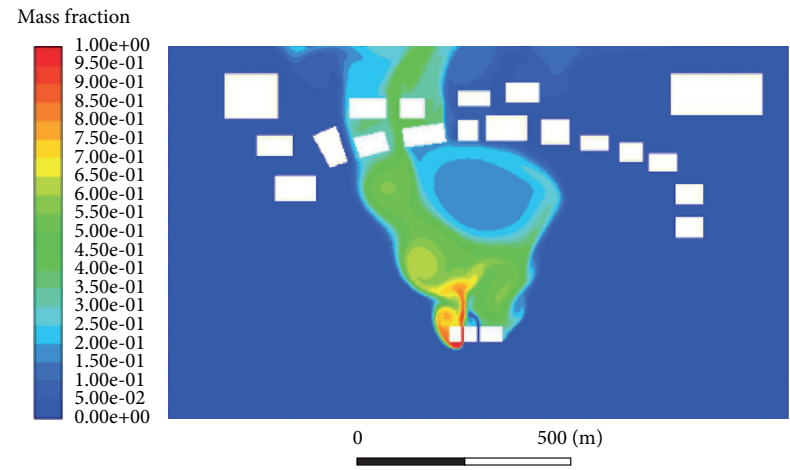

FIgURE 13: Radionuclide distribution rotating $270^{\circ}$ clockwise at the southern break.

TABLE 4: The dangerous area and proportion after rotating at the southern break.

\begin{tabular}{|c|c|c|c|c|}
\hline \multirow[t]{2}{*}{ Rotation angle } & \multicolumn{2}{|c|}{ Island's dangerous area } & \multicolumn{2}{|c|}{$\begin{array}{c}\text { Dangerous area of } \\
\text { floating nuclear power } \\
\text { plant platform }\end{array}$} \\
\hline & Area $\left(\mathrm{m}^{2}\right)$ & Percentage & Area $\left(\mathrm{m}^{2}\right)$ & Percentage \\
\hline $0^{\circ}$ & 109140 & 24.7 & 1650 & 75.0 \\
\hline $90^{\circ}$ & 103360 & 23.4 & 1500 & 68.2 \\
\hline $180^{\circ}$ & 172040 & 38.9 & 978 & 44.5 \\
\hline $270^{\circ}$ & 129200 & 29.2 & 1500 & 68.2 \\
\hline
\end{tabular}

Contour-2

Mass fraction

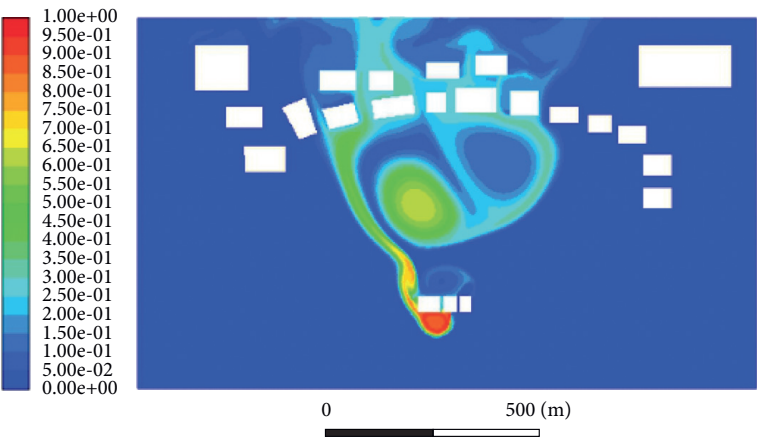

FIgURE 14: Radionuclide distribution rotating $90^{\circ}$ clockwise at the western break.

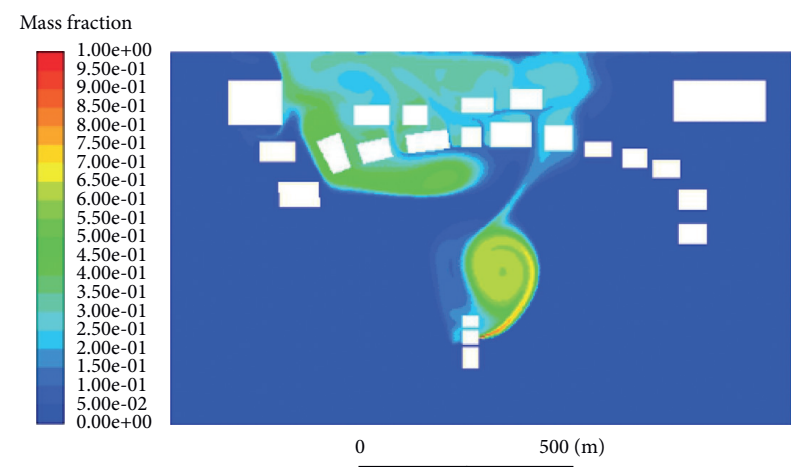

FIGURE 15: Radionuclide distribution rotating $180^{\circ}$ clockwise at the western break.

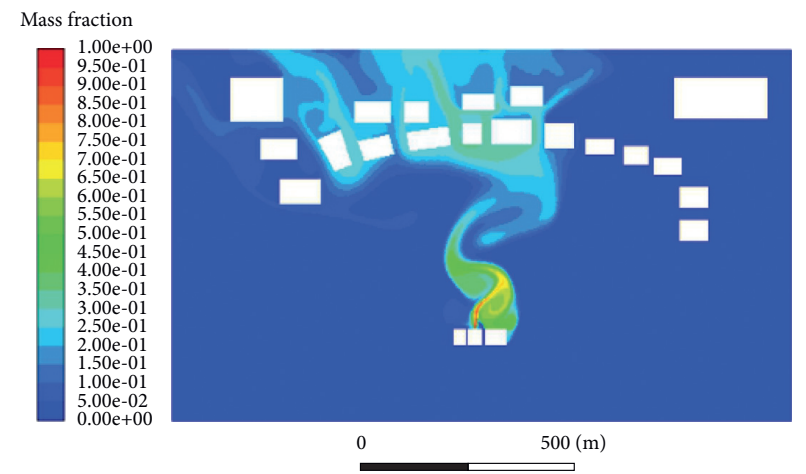

FIgURE 16: Radionuclide distribution rotating $270^{\circ}$ clockwise at the western break.

TABle 5: The dangerous area and proportion after rotating at the western break.

\begin{tabular}{|c|c|c|c|c|}
\hline \multirow[t]{2}{*}{ Rotation angle } & \multicolumn{2}{|c|}{ Island's dangerous area } & \multicolumn{2}{|c|}{$\begin{array}{c}\text { Dangerous area of } \\
\text { floating nuclear power } \\
\text { plant platform }\end{array}$} \\
\hline & Area $\left(\mathrm{m}^{2}\right)$ & Percentage & Area $\left(\mathrm{m}^{2}\right)$ & Percentage \\
\hline$\overline{0^{\circ}}$ & 191760 & 43.4 & 725 & 31.8 \\
\hline $90^{\circ}$ & 192440 & 43.5 & 1075 & 48.9 \\
\hline $180^{\circ}$ & 239360 & 54.2 & 1150 & 52.3 \\
\hline $270^{\circ}$ & 221000 & 50.0 & 700 & 31.8 \\
\hline
\end{tabular}




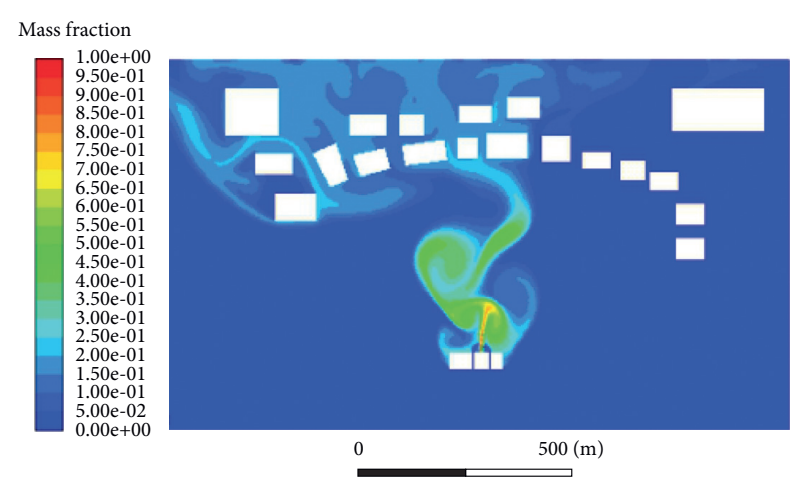

FIGURE 17: Radionuclide distribution rotating $90^{\circ}$ clockwise at the eastern break.

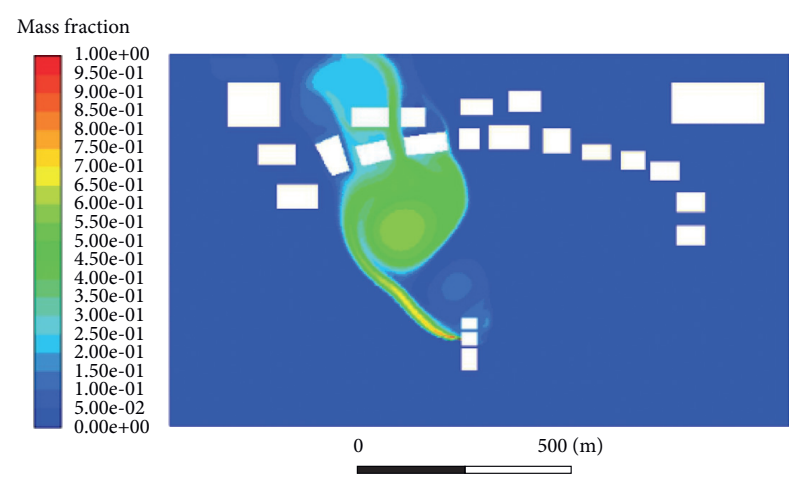

FIGURE 18: Radionuclide distribution rotating $180^{\circ}$ clockwise at the eastern break.

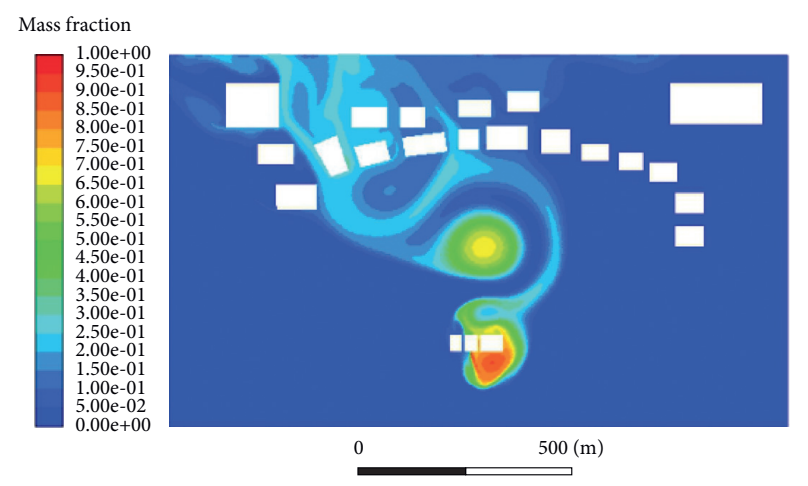

FIGURE 19: Radionuclide distribution rotating $270^{\circ}$ clockwise at the eastern break.

accounting for $60 \%$ of the total. When the platform rotates $270^{\circ}$ clockwise, the dangerous area of the island and the dangerous area of the platform are $19,510 \mathrm{~m}^{2}$, accounting for $119.5 \%$ of the total, so it can be better to rotate $90^{\circ}$ and $180^{\circ}$ clockwise to reduce the risk.

4.3. Results for Radiation Dose Assessment. According to the previous analysis, the break at south side (B) is the most unfavorable working condition. Therefore, the break at $\mathrm{B}$ is taken as an example to evaluate the radiation dose received by the workers and the public. Inhalation effective dose and
TABLE 6: The dangerous area and proportion after rotating at the eastern break.

\begin{tabular}{|c|c|c|c|c|}
\hline \multirow[t]{2}{*}{ Rotation angle } & \multicolumn{2}{|c|}{ Island dangerous area } & \multicolumn{2}{|c|}{$\begin{array}{c}\text { Dangerous area of } \\
\text { floating nuclear power } \\
\text { plant platform }\end{array}$} \\
\hline & Area $\left(\mathrm{m}^{2}\right)$ & Percentage & Area $\left(\mathrm{m}^{2}\right)$ & Percentage \\
\hline $0^{\circ}$ & 223400 & 50.5 & 1075 & 48.8 \\
\hline $90^{\circ}$ & 241400 & 54.6 & 850 & 38.6 \\
\hline $180^{\circ}$ & 144500 & 32.7 & 600 & 27.3 \\
\hline $270^{\circ}$ & 196860 & 44.5 & 1650 & 75 \\
\hline
\end{tabular}

TABLE 7: Radiation dose of floating platform staff within 2 hours after LOCA (unit: Sv).

\begin{tabular}{lcc}
\hline The type of radionuclides & Air intake & Plume immersion \\
\hline${ }^{133} \mathrm{Xe}$ & 0 & $6.94 \times 10^{-10}$ \\
${ }^{135} \mathrm{Xe}$ & 0 & $4.43 \times 10^{-10}$ \\
${ }^{131} \mathrm{I}$ & $4.23 \times 10^{-9}$ & $4.45 \times 10^{-12}$ \\
${ }^{132} \mathrm{I}$ & $1.34 \times 10^{-11}$ & $5.34 \times 10^{-12}$ \\
${ }^{133} \mathrm{I}$ & $2.89 \times 10^{-9}$ & $1.02 \times 10^{-10}$ \\
${ }^{134} \mathrm{I}$ & $3.01 \times 10^{-10}$ & $2.12 \times 10^{-9}$ \\
${ }^{135} \mathrm{I}$ & $2.11 \times 10^{-8}$ & $8.98 \times 10^{-10}$ \\
${ }^{134} \mathrm{Cs}$ & $5.12 \times 10^{-10}$ & $4.33 \times 10^{-12}$ \\
${ }^{137} \mathrm{Cs}$ & $3.12 \times 10^{-6}$ & $1.98 \times 10^{-12}$ \\
${ }^{133} \mathrm{Te}$ & $5.28 \times 10^{-5}$ & $5.35 \times 10^{-10}$ \\
${ }^{99} \mathrm{Mo}$ & $1.45 \times 10^{-5}$ & $4.23 \times 10^{-11}$ \\
Particle & $8.21 \times 10^{-3}$ & $4.89 \times 10^{-4}$ \\
Sum & $8.22 \times 10^{-3}$ & $4.90 \times 10^{-4}$ \\
Total dose & \multicolumn{2}{c}{$8.71 \times 10^{-3}$} \\
\hline
\end{tabular}

the effective dose of plume immersion exposure are shown in Table 7.

As shown in Table 7, within 2 hours after LOCA of floating nuclear power plant, the total radiation dose received by the workers on the platform by air inhalation and plume immersion is $8.71 \times 10^{-3} \mathrm{~Sv}$, which is less than $0.25 \mathrm{~Sv}$ (the dose limit in GB 6249-2011).

\section{Summary and Conclusions}

(1) Taking the floating nuclear power plant platform as the research object, this paper analyzes the radionuclide dispersion law of the combination of platform position, wind direction, and platform break direction in the loss-of-coolant accident based on CFD. The dangerous area is different at different breaks, indicating that the layout of the platform has a greater impact on the radionuclide dispersion.

(2) When nuclear leakage occurs on the floating nuclear power plant platform, the hull can be rotated at an appropriate angle to reduce the risk of accidents.

(3) The radiation dose received by personnel under severe accident was evaluated, and the results showed that inhalation effective dose and the effective dose of plume immersion exposure within two hours after the accident were both less than the radiation dose limit of $0.25 \mathrm{~Sv}$.

(4) By studying the impact of the location of the break and the placement of the hull on radionuclide 
dispersion, it is known that during the design of floating nuclear power plants and the formulation of emergency plans, the impact of the layout of the nuclear power plant platform on radionuclide dispersion should be considered, so as to formulate corresponding emergency measures.

\section{Nomenclature}

$\rho: \quad$ Fluid density $\left(\mathrm{kg} / \mathrm{m}^{3}\right)$

T: $\quad$ Thermodynamic temperature $(\mathrm{K})$

$\mathrm{t}$ : $\quad$ Time (s)

$C p$ : Thermal conductivity of the fluid $(\mathrm{W} / \mathrm{m} \mathrm{k})$

$u$ : Velocity vector in $x$ direction $(\mathrm{m} / \mathrm{s})$

$\mu$ : Dynamic viscosity (pa s)

$v$ : Velocity vector in $y$ direction $(\mathrm{m} / \mathrm{s})$

$C: \quad$ Gas volume concentration $\left(\mathrm{ml} / \mathrm{m}^{3}\right)$

$w$ : Velocity vector in $z$ direction $(\mathrm{m} / \mathrm{s})$

$T_{C}$ : Gas diffusion coefficient $\left(\mathrm{m}^{2} / \mathrm{s}\right)$

$S_{C}$ : Component production rate per unit volume $\left(\mathrm{kg} / \mathrm{s} \cdot \mathrm{m}^{3}\right)$

$\tau_{i j}$ : Viscous stress tensor $\left(\mathrm{N} / \mathrm{m}^{2}\right)$

$g_{i}$ : Gravitation acceleration in $x_{\mathrm{i}}$ direction $\left(\mathrm{m} / \mathrm{s}^{2}\right)$

$\lambda$ : Thermal conductivity of the fluid (W/m k)

$\bar{\mu}_{i}$ : Time-averaged velocity $(\mathrm{m} / \mathrm{s})$

$\bar{\mu}_{j}$ : Time-averaged velocity $(\mathrm{m} / \mathrm{s})$.

\section{Data Availability}

The data used to support the findings of this study are included within the article.

\section{Conflicts of Interest}

The authors declare that they have no conflicts of interest.

\section{Acknowledgments}

The authors acknowledge the support provided by the Nuclear Power Technology Innovation Program for $\mathrm{Na}$ tional Defense Technology Industry of China (HDLCXZX2020-ZH-013).

\section{References}

[1] S. Wang, B. W. Yang, Z. Zhou, and J. Long, "Review on thermal-hydraulic characteristics of nuclear reactors under ocean conditions," Nuclear Science and Engineering, vol. 193, no. 1-2, pp. 14-32, 2019.

[2] M. Rafiul Abdussami, T. Alam, A. H. M. Iftekharul Ferdous, and G. N. Rahman, "Overview and prospect of off-shore floating nuclear power plant in Bangladesh," European Journal of Engineering Research and Science, vol. 1, no. 6, pp. 654-663, 2016.

[3] J. K. Paik and J. H. Park, "Impact crashworthiness of a floating offshore nuclear power plant hull structure in a terrorist attack with an aircraft strike," Ships and Offshore Structures, vol. 15, no. 1, pp. 1-14, 2020.

[4] K. Geon-Woo, P. Goon-Cherl, and C. Hyoung Kyu, "Scaling analysis for single-phase natural circulation under dynamic motion and its verification using MARS-KS code," Annals of Nuclear Energy, vol. 159, Article ID 108308, 2021.
[5] J. Qiu, L. Li, Y. Tai, S. Yao, G. H. Su, and S. Qiu, "MELCOR simulation of the SBLOCA induced severe accident for the SMR in a floating nuclear power plant," Progress in Nuclear Energy, vol. 129, no. 3, Article ID 103509, 2020.

[6] M. Bellegoni, F. Ovidi, G. Landucci, L. Tognotti, and C. Galletti, "CFD analysis of the influence of a perimeter wall on the natural gas dispersion from an LNG pool," Process Safety and Environmental Protection, vol. 148, pp. 751-764, 2021.

[7] M. Bayatian, M. R. Azari, K. Ashrafi, M. J. Jafari, and Y. Mehrabi, "CFD simulation for dispersion of benzene at a petroleum refinery in diverse atmospheric conditions," Environmental Science and Pollution Research, vol. 28, no. 25, pp. 32973-32984, 2021.

[8] R. Rabi and L. Oufni, "Study of radon dispersion in typical dwelling using CFD modeling combined with passive-active measurements," Radiation Physics and Chemistry, vol. 139, pp. 40-48, 2017.

[9] C. Lin, R. Ooka, H. Kikumoto, T. Sato, and M. Arai, "CFD simulations on high-buoyancy gas dispersion in the wake of an isolated cubic building using steady RANS model and LES," Building and Environment, vol. 188, Article ID 107478, 2021.

[10] Y.-H. Wang, Y. P. Lin, H. Y. Chang, and C.-M. Lai, "Ventilation pattern and heat dissipation characteristics of a vertical dry storage cask for spent nuclear fuel: wind tunnel experiments and CFD simulations," Annals of Nuclear Energy, vol. 160, Article ID 108364, 2021.

[11] P. K. Bhowmik and K. Y. Suh, "Flow mapping using 3D fullscale CFD simulation and hydrodynamic experiments of an ultra-supercritical turbine's combined valve for nuclear power plant," International Journal of Energy and Environmental Engineering, vol. 12, no. 3, pp. 365-381, 2021.

[12] H. Xiaodong, L. Fuyu, W. Yanhui, and L. Qinlei, "Research on flow stable performance of venturi tube for nuclear power system based on fluent," Nuclear Power Engineering, vol. 39, no. 4, pp. 32-36, 2018.

[13] H. Lin, Research on the Numerical Modeling of Offshore Radioradionuclide Dispersion Based on CFD, Hefei: University of Science and Technology of China, Hefei, China, 2018.

[14] P. A. B. D. Sampaio, M. A. G. Junior, and C. M. F. Lapa, “A CFD approach to the atmospheric dispersion of radioradionuclides in the vicinity of NPPs," Nuclear Engineering \& Design, vol. 238, pp. 250-273, 2007.

[15] X. Wang, G. Wei, S. Wang, Y. Yang, D. Fenglei, and B. Wang, "Impact of large cooling tower on atmospheric dispersion of effluent from coastal nuclear power plant," Journal of Coastal Research, vol. 103, no. s1, 2020.

[16] G. Thomas, P. Emmanuel, C. Christophe, D. Ioana, J. Christophe, and R. Damien, "Development and validation of an agglomeration model for CFD simulations of aerosol dispersion in the frame of Fukushima fuel debris retrieval," Journal of Nuclear Science and Technology, vol. 58, no. 6, 2021. 